\title{
Aligning Reverse Logistics into a Sustainable and Scalable Business Organization - A Benchmarking Study in High-Tech Industry ${ }^{+}$
}

\author{
Jung Ung Min* and Hun-Koo $\mathrm{Ha}^{* *}$
}

\begin{abstract}
Reverse logistics has been seen as a necessary cost of business, but more companies are seeing it as a core strategic activity. Every firm needs to find more efficicient ways of reclaiming, redistributing, and disposing returns. For a fast growing industry, however, it is difficult to focus on structuring internal processes for reverse logistics because its emphasis is always on time to market and growing sales. In order to capture the most updated trend in the field of reverse logistics, this paper describes best practices of reverse logistics in hi-tech industry and identifies barriers in implementing those practices. The focus areas of the benchmarking survey are outsourcing of the logistics function, organization of the logistics function, return management, and sustainability-green issue. Based on the survey results, we provide an insight for capturing these trends and leveraging them as a strategic core competency for this industry.
\end{abstract}

Keyword: Reverse Logistics, Benchmarking, Hi-tech industry, Outsourcing, Sustainability

Submission Date: 1/23/2006 Acceptance Date: 5/29/2006

* Professor, Asia Pacific School of Logistics, Inha University, 253 Yonghyun-dong, Nam-gu Incheon 402-751, Korea.

** Coresponding Author: Professor, Asia Pacific School of Logistics, Inha University, 253 Yonghyun-dong, Nam-Ku, Incheon 402-751, Korea,. E-mail: hkha@inha.ac.kr.

${ }^{+}$This work was supported by INHA UNIVERSITY Research Grant. (INHA-34085) 


\section{REVERSE LOGISTICS IN HIGH-TECH INDUSTRY}

Traditionally, reverse logistics has been seen as a necessary cost of business, or a "green" initiatives, but more companies are seeing it as a core strategic activity (Mollenkopf and Closs, 2005). Reverse logistics is becoming more than a sub-process of product return - rather, it is a major driver of securing competitive advantage in the age of demanding customers with shorter life cycle. Every firm needs to find more efficicient ways of reclaiming, redistributing, and disposing returns. Reverse logistics is defined by Reverse Logistics Executive Council as:

"The process of planning, implementing, and controlling the efficient, cost effective flow of raw materials, in-process inventory, finished goods and related information from the point of consumption to the point of origin for the purpose of recapturing value or proper disposal (Rogers and Tibben-Lembke, 1998)."

Reverse Logistics by its nature is a very complex and specialized area of any supply chain. No matter what the product is, how it is sold, or who the customers are, every company needs to focus on recovering the greatest value from returns.

In general, logistics plays a key role in hi-tech products as it does in general consumer goods. It is the key for manufacturing since the efficiency in inbound logistics determines the base cost of production. High-tech companies such as Juniper Networks, Sun Microsystems, and Hewlett Packard concentrate on technology, design, marketing and sales, and hence these companies have increasingly outsourced their manufacturing to electronic contract manufacturers such as Solectron, Celestica, Jabil Circuits and Sanmina. As a result, inbound logistics (sourcing raw materials for manufacturing) is largely managed by the contract manufacturers. On the other hand, outbound logistics (distribution) and reverse logistics is still being managed by some hi-tech companies themselves even though they don't feel that it is one of their core competencies. One of the major reasons for this lack of outsourcing in outbound logistics and reverse logistic would be that logistics is a core part of the customer service provided by the companies. As customer satisfaction is crucial for retaining market share, hi-tech companies don't feel comfortable in ceding control over logistics to service providers.

Here, the problem is that companies don't have the time and resources to focus on structuring internal processes for reverse logistics while maintaining competitiveness in such a fast growing industry. The emphasis is always on time to market and growing sales, while functions such as operations and manufacturing are often handled with fire 
fighting on a daily basis. There is virtually no time to focus on structuring the internal processes and using some of the best practices in the industry.

This paper describes best practices of reverse logistics in hi-tech industry and identifies barriers in implementing those practices. Further, we provide an insight for capturing these trends and leveraging them as a strategic core competency for this industry.

\section{BEST PRACTICES IN REVERSE LOGISTICS: LITERATURE REVIEW}

In terms of current practices in reverse logistics, Rogers and Tibben-Lembke did extensive research through interviewing over 150 managers with reverse logistics responsibilities (Rogers and Tibben-Lembke, 2001). They provided an overview of the approximate size of reverse logisctics, detailed activities associated with it, the general trend of return policy, and the pros and cons of the centralized return processing (central return center, $\mathrm{CRC}$ ). This work was an exploratory research study that gave an interesting aspect of reverse logistics in general. However, their research missed a very important aspect of reverse logistics: outsourcing. As noted earlier, it is critical for hitech industry to look at reverse logistics from the outsourcing perspective because it is not their core competency but is still critical as a customer contact point. Furthermore, their research did not describe organizational structure for dealing with challenges in reverse logistics. Similarly Beltran described current practices of 10 key reverse logistics management elements but explained the outsourcing aspect of reverse logistics very briefly only within the context of other elements (Beltran, 2002).

In terms of outsourcing reverse logistics, Meade and Sarkis argued that the selection process of third-party reverse logistics providers has some similarities with general vendor selection but includes additional external factors due to its unique requirements (Meade and Sarkis, 2002). In their research, they proposed a decisionmaking model for selecting and evaluating third-party organizations considering the location of product and the requirements of the organization's reverse logistics process function (Meade and Sarkis, 2002). However, their research effort has put more on the detailed operational side rather than the strategic aspect of outsourcing reverse logistics. 
Although some researchers have criticized that most publications in the field of reverse logistics have appeared in practitioner-oriented publications (Carter and Ellram, 1998), it is still important to identify the best practices and utilize them as a significant source for developing research models and theory as well as for business management. We focus our discussion on the most recent best practices of global companies in hitech industry, which we belive it as the most valuable resources for future research and for industry practitioners.

\section{RESEARCH DESCRIPTION}

The research team interviewed five hi-tech companies and three logistics service providers in the U.S so as to find out the exisiting best practices. Their annual sales in 2004 are illustrated in Figure 1.

We developed two questionnaires, one targeted toward the participating manufacturers, and the other toward the service providers. The focus areas of the benchmarking survey were outsourcing of the logistics function, organization of the logistics function, return management, and sustainability-green issues. Rationale for selecting these four focus areas are described in the following.

Figure 1. Annual Sale of Participating Companies

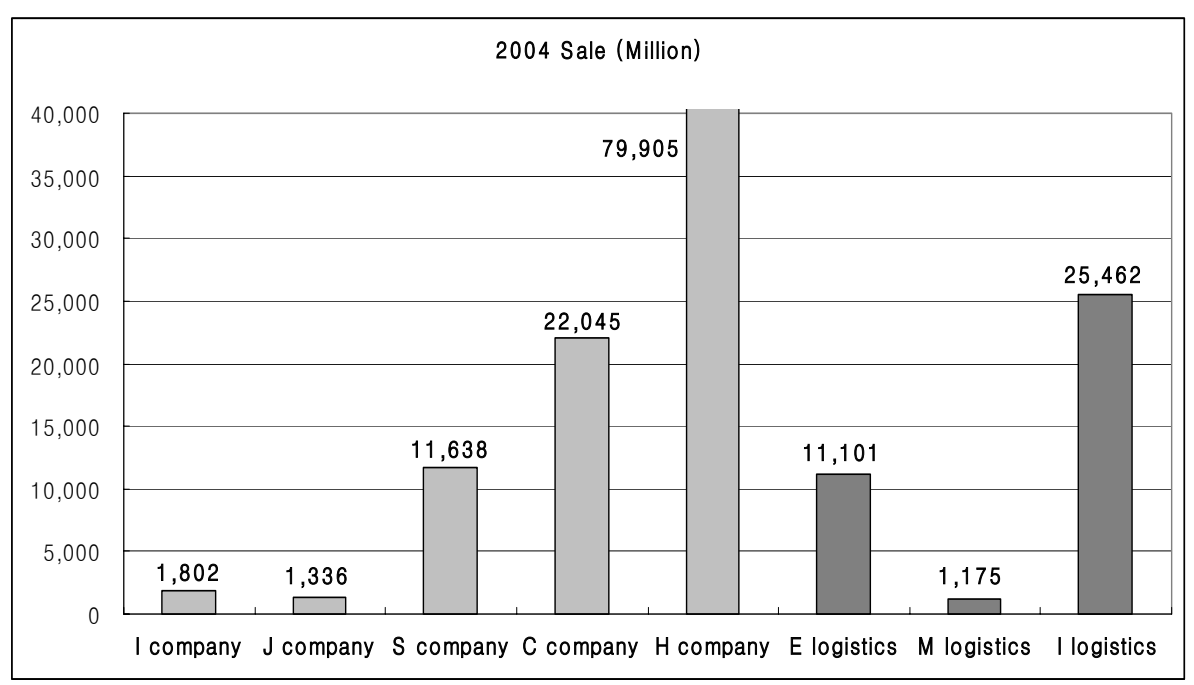




\subsection{Outsourcing of the logistic function}

Increasingly, companies are outsourcing their logistics. According to a survey by Accenture and Northeastern University, more than 70 percent of Fortune 500 companies have outsourced at least one major logistics function such as transportation management, freight payment, warehouse management, shipment tracking or other transportationrelated functions (Wilson, 2001). Major reasons for outsourcing are as follows:

First, companies consider outsourcing to reduce total logistics costs. These include transportation costs, warehousing costs, and inventory costs associated with the current provision of logistics. Other financial reasons include improving ROA by divesting (or not investing in) warehouses, transportation facilities/equipment, etc. Leveraging third parties that specialize in logistics would allow companies to efficiently deliver or recover products. By comparison, in-house logistics would be a fixed cost and more difficult to adjust through the business cycle ups and downs.

Secondly, companies whose logistic capabilities are strategically important may enhance their key logistic capabilities by outsourcing. Outsourcing may shorten the lead-time for logistics, increase accuracy, or allow more product customization through increased flexibility. For example, Zara, the Spanish fashion company, leverages its internal production and distribution systems to allow it to go from design to delivery in stores in just three weeks; by comparison, rivals H\&M and the Gap can take up to 5 months for the design to delivery process, and the industry average is 9 months. ${ }^{1}$

Thirdly, companies may pursue outsourcing in order to focus on enhancing their key capabilities, while leaving logistics, which is often not considered as a core competency, to expert providers. For example, high-tech companies may focus more on $\mathrm{R} \& \mathrm{D}$ or product development and avoid allocating management attention and resources to logistics.

Fourth, the increasingly complex coordination of logistics functions among various transportation providers can often best be left to a specialist 3PL provider.

Often, the decision to outsource involves some combination of the above reasons, but it is not clear whether those would be also true in the case of reverse logistics.

\footnotetext{
1 "Floating on Air: Spain's Successful Zara: a Mixture of Vertical Integration and Street Smarts has Transformed a Small Spanish Clothing Chain into a Global Success," The Economist, 5/9/01.
} 


\subsection{Organization of the logistics function}

Companies face different challenges in how they should structure their logistics organization. Some challenges are driven by the growth of the companies, while others are driven by the changes in the competitive landscape. One of the major challenges an increasing number of companies will face in the future is how a company should reorganize itself to strengthen its reverse logistics. Reverse logistics is increasing in importance as cost-effective customer service becomes a higher priority. Companies have been focused on organizing forward logistics for some time, and hence we have focused on the organizational structure challenges companies face in implementing reverse logistics capabilities.

Effective reverse logistics can achieve benefits such as reductions in inventory cost, transportation, and waste disposal costs, as well as improved customer service. Nevertheless, companies are caught in a dilemma: to implement reverse logistics, they need to employ staff in designated departments to deal with customers. Furthermore, once a product is returned, it has to be serviced or destroyed which often incurs considerable costs. On the other hand, if firms are inefficient in returns, they may lose customers. Therefore, companies must find a cost-effective and productive method of handling the reverse logistics process.

\subsection{Product returns}

Returns management for benchmarking purposes is focused on the return of failed products. In the case of hi-tech products such as routers, if an individual router fails, it usually doesn't bring down the entire network. The customer needs to schedule a repair during the next available maintenance window when network traffic is the lowest. Therefore, the customer demands from the equipment provider that a replacement part be available for that maintenance window and upon completion of the repair, it is the customer's responsibility to ship the product back to the equipment provider. Once the replacement part is received by the customer, however, the incentive for the customer to return the failed part is low. From the equipment provider's point of view, it is imperative that the failed part be returned promptly so that an appropriate failure analysis can be conducted. Prompt failure analysis not only allows the equipment provider to pro-actively replace similarly defective parts or modify designs or manufacturing processes to improve the quality of the part, but also to improve the quality of future generations of the part. In addition, if failed parts are outstanding, they 
can't be refurbished and added to the replacement part inventory; this leads to an increase in the inventory holding cost.

\subsection{Designing and delivering products in a sustainable manner}

The sustainability aspect of reverse logistics is reflected in the definition mentioned earlier (Rogers and Tibben-Lembke, 1998) : "the process of planning, implementing, and controlling the efficient, cost effective flow of materials, in-process inventory, finished goods, and related information from the point of consumption to the point of origin for the purpose of recapturing value or proper disposal." There are three main reasons why a customer might return a product: the product is defective, a customer is upgrading / product obsolescence, and a product has reached end of its life. Returns of defective products allow the company to conduct failure analysis and refurbish for resale. Returns of products when a customer upgrades allows the company to resell to secondary markets. Returns of end of life products is largely a goodwill measure, but potentially could provide the company with cost savings if parts can be re-used, the product can be remanufactured, or the materials can be reclaimed or recycled. The fourth issue that this research focuses on is on the last type of return, that is, product sustainability in the sense of closing the product life cycle loop. In addition to product returns, there are also packaging returns, which will not be addressed in this benchmarking research.

\section{DISCUSSION OF BENCHMARKING SURVEY}

\subsection{Outsourcing of logistics in companies}

\subsubsection{Considerations for outsourcing reverse logistics}

Our research and interviews with companies that have outsourced logistics suggest that companies need to consider the following points before proceeding with outsourcing of reverse logistics. While these points are more qualitative than quantitative, they serve as a checklist for companies proceeding with outsourcing. 


\section{Select your partners based on value not cost}

Many companies pursue outsourcing to lower costs. Focusing solely on cost, however, may not allow companies to fully benefit from outsourcing. Companies can benefit from an option that is costlier than an alternative, if the additional value provided by the former is much larger. For example, choosing an option with a higher cost may greatly improve customer satisfaction, thus generating more revenues.

Our interviewees also indicated that it is more important to focus on value provided by outsourcing. For example, an interviewees of 3PL company provides its clients not only with lower logistics costs than customers would incur for in-house development and maintenance of such systems; as a logistics provider it invests heavily in implementing systems using the most effective technology available, and is able to provide customized solutions to its clients in a timely manner. In another case of value and not merely cost driving the outsourcing decision, a software company notes that a core competency analysis and the changing market demands drove it towards outsourcing, and once outsourcing was decided upon, the primary objectives were improved customer service through higher order completion and on-time metrics, as well as a leveraged buy on transportation needs. Outsourcing did, in fact, incur a slightly higher overall model cost, although the variable cost structure was seen as essential to the software maker.

\section{Structure for quick decision making}

Outsourcing is structured across the company and its outsourcing partners so that the company can make quick and timely decisions. This involves creating an efficient flow of information to allow collaborative decision-making.

A network equipment manufacturer stressed the importance of quick decisionmaking processes as being the goal and objective in partnering with third parties. It also emphasized the need to clarify roles and responsibilities and to understand which party can make which decisions.

\section{Empower providers: understand their goals, motives and requirements}

Companies also need to understand the goals, motives, and requirements of the outsourcing partner to construct an effective long-term relationship. Better understanding between the parties enables the company to motivate the outsourcing partner in ways that will benefit the company. 


\section{Understand the expertise of the partner: use the alliance expertise and assets}

Outsourcing service providers often have different focuses, strengths, and weaknesses. One provider may focus more on consumer goods, while others may specialize in hightech, highly customized products. Companies need to choose service providers based on which area requires most attention, and which capabilities (expertise and assets) the partners have in order to address the issues at hand. Clarifying and mapping the needs of the companies and the capabilities of the partners is essential. For example, a network equipment manufacturer, which is focusing on expanding its global reach, the expertise and assets necessary for global coverage will be critical.

\section{Internal consensus / buy in}

Internal consensus on outsourcing is essential. First, it requires company-wide participation to outsource logistics or any other part of the supply chain. In the case of a computer manufacturer, a joint executive committee was formed, as well as joint project management teams to develop alliance management processes, establish project evaluation plans and controls, prepare status reports, and monitor and evaluate recommendations to address specific needs. Internal consensus also must be squarely behind the reallocation of both human and capital resources. Any absence of internal consensus will greatly hamper the process of putting in place essential initiatives and teams to facilitate the outsourcing process.

Secondly, especially for companies that already have in-house capabilities, outsourcing affects employment, changes in organizational structure, and processes. General inertia can prevent a company from quickly implementing the necessary changes. Part of the problem is the dual risk the company faces if outsourcing goes awry: if the outsourcing provider fails to deliver, customers are dissatisfied and go elsewhere, and in-house logistics people have been terminated or redeployed, leaving the organization exposed.

\section{Share rewards and risks}

The partnership needs to be formed so that the rewards and risks are shared by the company as well as by the outsourcing service providers. This will align the interests of the service providers with that of the company and will also motivate the providers to enhance their capabilities to better serve the company. For example, a 3PL service provider notes that as customers often initially can't quantify the details of the activity to be outsourced, such as the cost per transaction, it often structures its contracts on a 
cost-sharing basis, where both the 3PL company and its client stand to benefit by sharing any cost-saving gain.

\section{Clear performance evaluation}

Incentive and penalties need to be based on performance against standards. Clear performance measurement and assumption of responsibilities is critical. Furthermore, companies need to be aware of some pitfalls in establishing performance measures including:

- Measurement of less relevant performance

- Lack of accuracy

- Lack of proper balance between conflicting measures

- Lack of timeliness and dynamic tracking of measurements

- Outweighing of cost over benefit of measurement

- Lack of ability to identify and prevent metrics tinkering

A software company points to customer requirements as the key factors shaping logistics metrics; usually these come down to the accuracy and the completeness of orders, whether the orders are on-time, and the cost of service. A networking company, while it did not elaborate on it, stated that they saw this as an extremely important factor to consider.

\section{Focus on what and how to control rather than how much you control}

Companies tend to be reluctant to turn processes over to third parties. Thus, many seem to focus more on how much control they will give to the partner. Our interviews with companies suggested that companies benefit greatly from focusing more on what and how to control rather than how much to control. For example, a computer manufacturer has suggested that companies can outsource most of their logistics and have a minimum staff. If a company has the ability to monitor the performance and make timely decisions, it can outsource much of its logistics. A 3PL service provider concurs, noting that although it is critical for the outsourcing company to retain a liaison expert in supply chain management to manage the relationship with 3PL, the client no longer needs to maintain personnel for day-to-day logistics execution. It prides itself on the visibility and reporting it provides clients, which allows them to quantify logistics performance on a monthly and annual basis. 


\subsubsection{Considerations for selecting outsourcing partners}

Once the company is ready to proceed with outsourcing, it needs to select an outsourcing partner. Below are some of the key questions that companies need to assess based on this research.

\section{Outsourcing partners who know themselves; understand their cost structure}

In order to establish an effective partnership by sharing rewards and risks as well as implementing relevant performance evaluations, companies need to select partners that understand their cost structure among other metrics. A 3PL service providers notes that the key benchmarking criteria used by its clients are variations of the following factors: cost, quality of service provided, and inventory accuracy. Clients differ as to how benchmarking criteria are prioritized, but whichever metrics are decided upon, it usually charges a base cost and receives a bonus tied to how well it has met the customerdefined metrics.

\section{Longevity - long-term commitment}

Given the magnitude of commitment on the part of both parties, the outsourcing partner must be able to provide a long-term commitment in working together to continuously maintain and improve the outsourcing program. Furthermore, partners need to be financially stable to facilitate long-term contracts.

\section{Partnership philosophy - win/win}

It is crucial that the partner has a win/win philosophy in entering into the outsourcing program. In order to share the rewards and risks between the partners, it is important that the partner recognizes that both parties will benefit from a win/win philosophy in the long run, rather than trying to outdo each other for short-term benefits. The cooperative relationship based on win/win is also essential in giving both parties the incentives to improve the outsourcing program.

\section{Depth and breadth of relevant logistics expertise}

It is essential that the partners have the relevant logistics expertise to achieve the goals of the client company. 3PL companies that we surveyed have the depth and breadth of requisite expertise, ranging from transportation and warehousing to supply chain solutions. 


\section{Responsiveness}

Outsourcing program and its objectives constantly change and evolve. Partners must have the capability to respond promptly to such changes to be able to provide optimal service.

\section{Willingness to go beyond current offerings/services to meet requirements}

The scope and focus as well as the objective of the outsourcing programs change continuously. During the long-term partnerships, companies may decide to enter new verticals, change the logistics, and focus on new issues. Partners must have the capability to build new expertise and reach to serve the company in the long run. Furthermore, partners that share strategies (which future markets to focus on, etc.) will be important. A network equipment manufacturer, for example, pointed out that this was an essential element they seek in a partner.

\subsection{Organizational Structure of Logistics Function - How to organize reverse logistics?}

Implementing reverse logistics has challenges in two stages. First, before even making any organizational structure changes, companies face the challenge of getting company buy-in on a reverse logistics initiative. Many companies fail to recognize the value of reverse logistics, how much of a commitment is necessary, and what the pitfalls are in incorporating reverse logistic capabilities.

To provide a means of identifying major problems and difficulties associated with the planning, implementation and control of reverse logistics strategies and programs, Stock offered the following list of reverse logistics sins (Stock, 2001).

- Not recognizing that reverse logistics can be a factor in creating a competitive advantage.

- Believing that once products are delivered, the firm's responsibilities end

- Failure to match internal and external systems and processes in e-commerce and the product returns aspect of reverse logistics.

- Assuming that part-time effort is sufficient to deal with reverse logistics activities.

- Believing that order cycle times for product returns can be longer and more variable than those for new items being sold or distributed.

- Assuming that product returns and packaging recycling and reuse will take care of themselves if given enough time. 
- Thinking that returns are relatively unimportant in terms of costs, asset valuation and potential revenues.

Based on these misperceptions, we have indentified the following insights for organizing reverse logistics function in a company.

\subsubsection{Implementing Organizational Structure Challenges}

First, in order to overcome the issues of low recognition, misperceptions, and inertia, companies that are implementing reverse logistics need to create an organization (i.e. logistics department) that have power and credibility. One solution is to place a vice president of logistics in charge of the group as one of the interviewees indicated. Another is to have the group report to the chief officers directly. Companies need to make sure that the newly established organization can cope effectively with the inertia.

Secondly, a major challenge for companies is how to coordinate reverse logistics with the existing forward logistics function. Most of the companies we studied have centralized their logistics function under one or two vice presidents, and focus on forward logistics. For example, a software company has a small and focused internal logistics group under one vice president, operating under a functional matrix. A network equipment manufacturer's logistics function, which is under two vice presidents, does focus on the return of failed product and failure analysis, which has a high financial and customer service impact on its operations.

\subsubsection{Outsourcing}

Given the trend towards outsourcing, our research focused on some of the key points regarding outsourcing reverse logistics.

As we have discussed earlier, more and more companies are outsourcing reverse logistics as well as its forward logistics. Companies need to coordinate with their partners on how to outsource both logistics functions. A computer manufacturer, for example, involved management and established committees and teams to manage the new logistics processes. It sets up an "Executive Steering Committee" with its partner that was jointly formed by the management of both parties, that monitored and evaluated recommendations, and addressed specific needs. The project was jointly managed and also involved product services, information systems and transportation. 


\subsection{Return Management}

The benchmark questions on return management could be categorized into four areas: the average return rate of defective parts, accounting, contractual issues, and outsourcing. By benchmarking the average return rate, a company can better understand whether its return rate lies outside of industry norms and needs to be improved. From a contractual standpoint, customers should be returning the defective product, but often, companies are intent on retaining customers and don't want to run the risk of angering them by holding them to contractual terms that are not of the highest priority. Understanding how often the defective part returns is a key clause in contracts and this would help companies better gauge in which situations a customer may or may not get angered.

\subsubsection{Average Return Rate over Time}

Some products are not returned after 180 days and are considered lost. In the telecommunication industry, this may be due to the carrier going bankrupt or due to the contact person leaving the company and the manufacturer not knowing whom to contact after he has left to retrieve the missing defective part. One technique to get the customer to return the part is to hire a "nagging" service. This service will call and/or e-mail the customer once per week to remind the customer to return the part.

\subsubsection{Accounting - Expense or Capitalize?}

Companies have different ways to deal with returns. Most companies expense the cost of the part at the time the part is originally shipped to the customer. To account for potential returns, they set up a returns account that consists of a percentage of total sales based on historical data and approved by the auditors.

\subsubsection{Contractual Issues}

In terms of the length of time given customers for returning parts, most contracts allow for 30,60 , or 90 days for the return but this is not enforced, due to the desire to maintain good customer relationships. Some companies do not invoice the customer for nonreturned parts because their accounting systems are not setup for this or they don't want to aggravate their customers. 


\subsubsection{Outsourcing}

Most companies have some form of outsourcing of reverse logistics, but it varies widely as to whether it is only one service provider who does both the collection and the repair, multiple service providers-one who does the collection and one who does the repair, inhouse repair and outsourced collection, or a combination of all three.

\subsubsection{Incentives for Returning Product}

The basic incentive for encouraging the return of products is to make the process as painless as possible for the customer. This could mean providing the boxes and shipping labels, in the case where there are many customers with low volumes of the product, or organizing individual collection runs in the case where there are a few customers with high volumes of the product. In general, for low cost commodity products, including computers, offering discounts on future purchases is often effective in increasing the return rate. For capital expenditure items, like heavy machinery and routers, incentives need to be customized to best fit a customer's processes and needs. Upon analyzing customers, trends might emerge for a group of customers who have similar processes and needs, and a single return incentive can be applied to the group.

\subsection{Sustainability}

Part of the importance in the need for addressing product end-of-life returns is due to the threat of regulation. The most restrictive product take-back laws in place are in Europe, particularly Germany; companies wishing to do business in Europe need to plan ahead to meet those laws or potential laws. Germany passed the Basic Law of Waste Management in 1993; this law is an attempt to move Germany towards a closed loop economy, in which all production will be reused or recycled with a minimal amount of production eventually being in the landfill (Rogers and Tibben-Lembke, 2001). An ordinance for automobile take-back went into effect in 1998, and more ordinances, including one for electronics waste, are in the pipeline. The EU has also proposed laws on the collection and recycling of electrical and electronic waste. Although these laws focus more on consumer electronics, it is not unreasonable to think that business in hitech products could be targeted in the future. Although regulations in the US are not as restrictive, the EPA (US Environmental Protection Agency) predicts that half of the existing landfills will close by 2005 - tougher regulations are likely to come. 


\subsubsection{Design for End of Life and Collection Programs}

Attaining a closed loop product life cycle depends on two factors: appropriate end of life strategy and collection of end of life products. Many characteristics play into the appropriate selection of an end of life strategy, but the main characteristics that influence the selection are the end-of-life path, the wear-out life, and technology cycle (Rose, Masui et al., 1998). End-of-Life Strategy needs to be addressed in the product design phase, taking into consideration the likelihood of the particular end-of-life path (Rose, Masui et al., 1998).

The second factor in closing the product life cycle loop is effective collection of the end-of-life product. Product take-back can be mandatory (e.g. packaging in Germany) or voluntary (e.g. IBM, Dell, and HP's computer recovery programs). In the case of mandatory returns, companies don't want customers to incur increased costs (Rose and Stevels, 2000), so the question is whether to punish those customers who don't comply. The punishment could be in terms of invoicing the customer if a product is not returned, or not giving the customer a rebate for the end-of-life product. A middle road sometimes is more effective where the company will gradually reduce the rebate or increase the charge; gradual reductions can serve as warnings to customers and reduce the likelihood of upsetting the customer. Another option is to tie return rates with pricing in future contracts, but this requires there be effective sharing of data between the reverse logistics organization and sales.

Most product take-back systems are voluntary and there are many examples of effective collection systems. The choice of a collection system will depend on how accurately the returns can be forecasted; the more steady the flow of returns or the more control the company has over the timing of the returns makes collection easier. In addition, the ideal collection system will be dependent on whether there is a large number of customers, each returning small quantities, or a small number of customers, each returning large quantities.

\subsubsection{Benchmark Trends}

Consumer-oriented products (commodities) with short product life cycles are under the product sustainability radar screen much more so than business-oriented (specialized) products with longer product life cycles. As such, those companies with more commoditized products were more likely to have recycling and reverse logistics programs in place. Larger, more established companies or companies where there is an 
internal champion for sustainability were also more likely to have programs in place. Sustainability is still seen as more of a marketing ploy or a way to attract good-will; however, in reality, companies can attain cost savings if the volumes are high. A great example is a computer manufacturer's laser toner cartridges where the 3PL company who is collecting them labels costs at about $\$ 2$, but each cartridge that is returned is valued at $\$ 20$. With a high enough product return rate, the computer manufacturer can cut raw material costs significantly. This company is in fact a leader in sustainability space: they have published an environmental policy, instituted recycling programs for all computers (not just their own), printers, and most laser and inkjet printer cartridges, is ISO 14001 certified, works towards worldwide environmental performance measures, reviews environmental performance of their suppliers, designs for the environment, and publishes environmental data sheets for all products. The intent is not only to lead technological innovation in this area and be an example to other companies, but also to gain economies of scale in terms of reverse logistics.

\section{CONCLUSIONS AND FUTURE OPPORTUNITIES}

In this research, we have interviewed eight companies in the US including manufacturers and third party service providers in search of the best practices in reverse logistics for sustainable and scalable business organization. The followings are the important points and trends noted during this benchmarking survey on four areas of focus: outsourcing of the logistics function, organization of the logistics function, return management, and sustainability-green issue.

- In logistics outsourcing, on time delivery by the logistics service provider is still an issue.

- Many big corporations have centralized logistics organizations (centralized at the corporate level). This leads to better policy and economies of scale. The downside, however, is that communications with the business units are often poor, and buy in from business units is difficult.

- Most companies have a logistics services division which provides all logistics related services to many OEMs (this includes complete logistical planning and complete reverse logistics activities including CRM capabilities (call centers). 
- Many organizations are utilizing internally developed systems for managing logistics.

- The most prevalent incentive for getting the defective product back is to give a discount on the purchase of new products, if the defective product is returned. A computer manufacturing company is able to extract nearly $\$ 20$ out of each returned cartridge when the cost of getting the defective back is only $\$ 2$.

- Design for disassembly is the key for economical reuse of defective products. Most companies are focused only on design for assembly, and not the other way round.

- Hi-tech companies are increasingly outsourcing their logistics activities, as it is not one of their core competencies.

- Organizational change management is the most important issue each company faces in cases of outsourcing. The financial cost of outsourcing comes next in importance.

- Companies use the software/systems of the logistics service providers and don't like to invest in buying their own software for logistics.

- Companies don't have the capability of real-time visibility. Many don't consider full visibility as important due to various reasons.

- Companies end up underfunding logistics departments, which inhibits people from running efficient operations.

- Cost, service and inventory accuracy are the most important performance metrics for logistics service providers.

Adding sustainability-green issue, one interviewee pointed out that products tend to have three failure rates at different points in time. The product might suffer a higher infant mortality rate on the first use, it might fail at a lower steady state rate during useful life, and it will fail at increasingly higher rates during product wear-out. The reverse logistics would have to handle volumes at these failure rates. Therefore it is very important for a company to plan ahead for the growth in volume of product returns. As the product ages, there will be a growth in returns for repair of specific parts that wear out or a growth in end-of-life product take-back. The high tech industry is one of rapid innovation; if the product improvement is great enough, there will also be a premature growth in product returns as companies upgrade their systems before products have reached the wear-out mode stage. Hi-tech companies who are ready to address reverse 
logistics issues will rate highly in customer satisfaction, enabling them to continue on their growth path.

\section{REFERENCES}

Beltran, L. S., 2002, "Reverse Logistics: Current Trends and Practices in the Commercial World," Logistics Spectrum, 36(3), 4-8.

Carter, C. R. and Ellram, L. M., 1998, "Reverse Logistics: A Review of the Literature and Framework for Future Investigation,” Journal of Business Logistics, 19(1), 85-102.

Meade, L. and Sarkis, J., 2002, "A Conceptual Model for Selecting and Evaluating Third-Party Reverse Logistics Providers," Supply Chain Management, 7(5), 283-295.

Mollenkopf, D. A. and Closs, D. J., 2005, "The Hidden Value in Reverse Logistics," Supply Chain Management Review, 9(5), 34-41.

Rogers, D. S. and Tibben-Lembke, R. S., 1998, Going Backwards: Reverse Logistics Trends and Practices, Reverse Logistics Executive Council.

Rogers, D. S. and Tibben-Lembke, R. S., 2001, “An Examination of Reverse Logistics Practices," Journal of Business Logistics, 22(2), 129-148.

Rose, C. M. et al., 1998, How Product Characteristics Determine End-of-Life Strategy, IEEE International Symposium for Electronics and the Environment Conference, Oak Brook, IL.

Rose, C. M. and Stevels, A., 2000, “Applying Environmental Value Chain Analysis to Product Take-Back Systems, "Proceedings of the 7th CIRP International Seminar on Life Cycle Engineering, Tokyo, Japn.

Stock, R. J., 2001, "The 7 Deadly Sins of Reverse Logistics," Material Handling Management, 56(3), 5-11.

Wilson, T., 2001, “Outsourcing Cuts Logistics Complexity,” Internetweek. 